Disponible en:

Miraguano Ediciones

Cl. Hermosilla, 104

28009 Madrid (España)

Telf.: +34 91 4014645

Fax: +34 91 4021843

E-mail: miraguano@miraguano-sa.es http://www.miraguano-sa.es/

\section{El Maestro Chooki Мотови y el Karate de OKInAwa}

POR KOHAKU IWAI

Madrid: Miraguano Ediciones, 2003

192 páginas. $24 \times 17 \mathrm{~cm}$. Ilustraciones

I.S.B.N.: $84-7813-263-5 \cdot 17 €$

\section{Revisión por Pablo Pereda González}

La edición del libro El Maestro Chooki Motobu y el Karate de Okinawa, escrito por Kohaku Iwai, basa su atractivo en erigirse como primera traducción al castellano de las dos publicaciones del maestro: Okinawa Kempo Karate Jutsu y Watashi No Karate Jutsu, que ocupan los dos primeros capítulos de los cuatro que componen la obra.

Poseo una de las copias del Okinawan Kempo, edición muy limitada, con el sabor nostálgico de lo antiguo. La obra original lleva el título mencionado, el que cito, y se compone de seis capítulos con diferentes secciones cada uno de ellos.

La versión al castellano se encuentra incompleta ya que sólo posee tres. El primero, muy corto, no se corresponde con el original. El capítulo quinto, este sí coincidente, totalmente fotográfico; sin duda el más atractivo y curioso. El capítulo seis, muy mutilado, dedicado a técnicas terapéuticas sólo aporta algunas consideraciones. No se incluyen aspectos importantes, entre ellos el dedicado a la medicina china con hierbas. Afortunadamente los amantes de la antropología pueden encontrar consejos ancestrales: para los vómitos de sangre recomienda un caldo de carne y hueso a base de maceraciones y mezclas determinadas. Vómitos de sangre no producidos por los golpes sino debidos a la tuberculosis que entonces arrasaba. Muchos maestros murieron por ella. El editor advierte, por si fuese menester, que ante cualquier problema de salud el lector acuda al centro médico más próximo

Es muy interesante la colección fotográfica de técnicas de kumite, sin duda históricas, de gran valor para los amantes e investigadores del Budo.

Del segundo libro, que compone el segundo capítulo Watashi No Karate Jutsu no puedo mostrar mi parecer, en el sentido de la comparación, puesto que desgraciadamente no poseo la versión original del mismo. Llama la atención de nuevo, eso sí, la colección de fotográfica y las técnicas desarrolladas en torno al kata Nai Fan Chi Shodan. Curiosamente en el original Okinawan Kempo Motobu habla de este kata y lo denomina Naihanchi y Nai-Hanchi con sus vertientes ichi, ni, san. De la lectura de este libro se desprende que Motobu enfocaba todo su kárate hacia el kumite; incluso habla de una posición de guardia de las manos totalmente diferente a la empleada en kárate clásico. Motobu mantiene planteamientos, muy realistas por cierto, sobre la primera máxima del kárate: "Nunca se empieza con un ataque". Lo entiende en un sentido diferente: el practicante no ha de buscar el enfrentamiento, pero si este se produce, debe atacar primero. Planteamientos muy cuestionados, entre otras cosas por su afición al kakedamashi, ejercicio consistente en acudir a lugares conflictivos para entrar en combate y poner en práctica lo aprendido.

Muy curiosa la relación de maestros de Budo que enumera, describiendo sus particularidades físicas y técnicas. Muchos de ellos totalmente anónimos; de ahí la gran riqueza de conocimientos que encerraba la isla de Okinawa.

Los capítulos dedicados al makiwara, reglas menores del kempo y técnica de kumite pertenecen al primer libro de Motobu Okinawan Kempo. El hecho de que aparezcan en Watashi No Karate Jutsu puede deberse a que el autor, Kohaku Iwai, no haya recibido los auténticos originales o bien a que haya preferido alterar los contenidos para que resulten más lógicos al concatenarse las dos obras hacia un público no experto.

El resto del libro lo componen dos capítulos: "Historia de las Técnicas de Lucha en Okinawa" y la "Historia de Ryu Kyu Kempo", ya totalmente diferentes los anteriores, escritas por el autor. Ambos se centran en aspectos históricos de la evolución del kárate hasta nuestros días, así como los diferentes estilos y maestros. Se echan de menos referencias al "Chuan Fa" y a maestros provenientes de esa línea que han tenido mucho peso específico en la evolución del Arte.

De la, por otra parte, interesante lectura del libro se deduce que los maestros mencionados pertenecían a una clase elevada y pudiente; el propio Motobu tenía parentesco con un príncipe de la isla. Funakoshi era un hombre letrado, Miyagi acaudalado y de buena familia. Motobu fue junto con Funakoshi quien exportó el kárate a Japón, después llegarían otros. Motobu no gozó de reconocimiento entre sus coetáneos que le tachaban de autodidacta; incluso menospreciaban su kárate tildándolo de karate kaken o callejero; todo esto por su afición a la pelea real con la cual, parece ser, puso en 
evidencia a todo aquél que se enfrentaba con él. Es curioso que ni Funakoshi ni el propio Motobu estuviesen presentes en la reunión del 36 para unificar katas en la cual sí se encontraba Miyagi. Todas estas cuestiones se plantean al lector desde la lectura detallada de este libro. Libro por cierto, englobado dentro de la tradición histórica y cultural del kárate; apto para los practicantes y público en general que deseen saber más sobre este arte pero que no busquen aplicaciones técnicas o prácticas de combate. Al estar centrado en la figura de Motobu lo considero imprescindible para cualquier artista marcial ya que de su lectura podrá sacar muchas conclusiones y deducciones lógicas que yo no voy a destapar aquí. Eso sí, el libro ofrece una visión muy particular de la historia del kárate a través de Kohaku Iwai. Evidentemente la historia y cultura del Kárate de Okinawa poseen matices mucho más amplios. La aportación de las obras de Motobu confieren al libro un valor añadido y merece la pena tenerlo en la biblioteca. Si no se conocen los originales de las obras, lo cual ocurrirá en la inmensa mayoría de los lectores, la mutilación de las mismas no tendrá mayor importancia para quien desee recrearse en la historia antigua del kárate y de sus protagonistas menos conocidos, al menos en Europa, como ocurre con el legendario Chooky Motobu.

\section{$\Leftrightarrow$}

El Sendero Pacífico. Guía de las Artes Marciales PARA NiÑos

Por Claudio Iedwab y Roxanne Standefer Barcelona: Ediciones Oniro, 2002

120 páginas. $23,5 \times 18,5 \mathrm{~cm}$. Ilustraciones I.S.B.N.: $84-9754-028-X \cdot 10,50 €$

\section{Revisión por Raquel Escobar Molina}

Con la obra El Sendero Pacífico, los autores Claudio ledwab y Roxanne Standefer nos ofrecen la visión más filosófica y educativa de las artes marciales. Se trata de un ejemplar didáctico, donde se presentan términos trascendentales como honestidad, disciplina, humildad, control personal o colaboración, valores que todo estudiante de artes marciales debe adquirir para aprender la lección más importante de todas: respeto al prójimo y a sí mismo.

Desde el punto de vista formal, El Sendero Pacífico proporciona una lectura amena, fácilmente asimilable, con un estilo sencillo y próximo al público a quien se dirige: los niños. El libro está dividido en diez capítulos, donde a través de cuentos y anécdotas se presentan temas significativos de forma clara, concisa y evitando excesivos tecnicismos que pueden entorpecer la comprensión del texto. Este lenguaje permite un acercamiento grato a las ideas que se quieren transmitir, aunque ocasionalmente los autores redundan en sus reflexiones.

El capítulo introductorio define vocablos tan característicos como Dojo y Sensei: el primero alude al lugar para aprender y actuar, donde la actitud más importante es la cortesía; el segundo se refiere al maestro, el que guiará al alumno en su aprendizaje. Mediante estos conceptos se pasa al capítulo siguiente, que versa sobre el comportamiento que un estudiante debe adoptar dentro del dojo, un auténtico ritual que se repite en cada sesión de trabajo. Así, cualquier tipo de tarea estará marcada por el respeto hacia la misma y hacia los compañeros/as que la realizan conjuntamente.

En el tercer capítulo se aclaran y secuencian las diferentes partes de una clase: el calentamiento, el aprendizaje de nuevas técnicas y el perfeccionamiento de las ya adquiridas. Para esto son imprescindibles la voluntad y el interés del alumno/a, además de la sabiduría del sensei para que todo el "proceso de aprendizaje sea divertido e interesante, saludable y amistoso".

El capítulo cuarto revela la consideración que tienen los cinturones para desmitificar juicios erróneos, ya que un color concreto determina la capacidad del estudiante para iniciarse en habilidades de un nivel superior y no el dominio total de los contenidos previos.

Avanzando en la lectura llegamos al quinto capítulo, donde se cuestiona la clasificación o no de las artes marciales como deporte, ya que su objetivo debe ser el crecimiento personal con independencia del resultado en el combate. Por su parte, en el sexto se sintetiza toda la doctrina, profundizando en los valores propios y encauzando la aplicación de éstos hacia la vida cotidiana. No obstante, la dificultad filosófica de los conceptos hace recomendable una explicación adicional del maestro.

El capítulo siete ofrece una visión más pragmática de las disciplinas marciales, ahondando en su utilización como defensa personal. Paralelamente se advierte que el fin último nunca debe ser la disputa y la lesión del contrario, sino el rechazo de la violencia y la protección de uno mismo. Una vez discernido el significado de arte marcial, el capítulo octavo presenta la plasmación de
Disponible en:

Ediciones Oniro

Cl. Muntaner $261,3^{\circ} 2^{a}$

0802 I Barcelona (España)

Telf.: +349320072 22

Fax: +34932007434

E-mail: oniro@edicionesoniro.com http://www.edicionesoniro.com/ 